\title{
Responses of planktonic larvae of the serpulid polychaete Spirobranchus polycerus var. augeneri to an alga, adult tubes and conspecific larvae
}

\author{
J. R. Marsden \\ Department of Biology, McGill University, 1205 Ave. Dr. Penfield, Montreal, Quebec, H3A 1B1 Canada \\ and \\ The Bellairs Research Institute of McGill University, St. James, Barbados
}

\begin{abstract}
Planktonic larvae, i.e. trochophores and metatrochophores of the tropical, gregarious serpulid Spirobranchus polycerus var. augeneri (ten Hove), showed no preference for Ulva lactuca, an alga common in the vicinity of adult worms. A preference for adult tubes was shown by 7 to $9 \mathrm{~d}$ old metatrochophores but not by younger stages. This preference may represent an early expression of a behaviour important in habitat selection at the time of settlement. Metatrochophores ( 4 to $8 \mathrm{~d}$ larvae) were attracted to other larvae of the same age that were progeny of the same group of parental worms. The interlarval attraction is not strong enough to have influenced the results of experiments testing other forms of larval response. A role for this behaviour in the formation of natural aggregations of larvae in the sea is possible but its assessment requires more understanding of larval sensitivity and the density of natural larval populations.
\end{abstract}

\section{INTRODUCTION}

A planktonic larval stage lasting hours to months is a part of the life cycle of many benthic marine invertebrates. This phase is generally considered to be an important determinant of dispersal, especially for sedentary species (Strathmann 1990). A largly unanswered question in marine biology concerns how larvae, at the end of a dispersal stage in the plankton, come to be located at settlement sites appropriate to the preferred habitat of the adult. Addressing this question requires a better understanding of the behaviour of planktonic larvae in response to environmental stimuli, as well as more information on the distribution of larvae in the field.

The behavioral responses of planktonic invertebrate larvae have been best documented for crustaceans in quantitative laboratory studies using environmentally relevant stimuli such as light, salinity and pressure (Doyle 1974, Forward \& Costlow 1974, Ennis 1975, Latz \& Forward 1977, Sulkin et al. 1980, Forward et al. 1984, O'Connor \& Epifano 1985, Forward 1989a, b, Ohman 1990). This work has led to the suggestion that the uneven distribution of larvae observed in the sea is a consequence of both passive transport in moving parcels of water and directional movement by larvae in response to physico-chemical cues (Mackas et al. 1985, Banse 1986, Jackson 1986). Much less is known about the distribution and behavioural capacities of smaller non-arthropod larvae (Hadfield 1986, Stancyk \& Feller 1986). Planktonic polychaete larvae have been shown to have a restricted distribution in a coastal bay (Mathivat-Lallier \& Cozaux 1990). Response to temperature change by bryozoan larvae has been correlated with their distribution in the field (Yoshioka 1986) and planktonic serpulid (Polychaete) larvae have been shown to respond to light (Young \& Chia 1982, Marsden $1984,1986,1988,1990$ ) and to water-borne exudates of the adult substrate (Marsden 1987, Marsden \& Meeuwig 1990, Marsden et al. 1990).

Chemoresponses, usually requiring contact, have been reported for many invertebrate larvae at the time of settlement (for reviews see Crisp 1974, Scheltema 1974, Hadfield 1986) but are less well known for planktonic larval stages. The demonstration that larvae of the tropical serpulid Spirobranchus respond positively to exudates of certain species of coral (Marsden 1987. Marsden \& Meeuwig 1990, Marsden et al. 1990) and reports that other planktonic organisms use chemical 
signals in feeding (Levandowsky \& Hauser 1978, Paffenhöfer et al. 1982, Koehl 1985, Van Alstyne 1986, Verity 1988), mating (Jacoby \& Youngbluth 1983) and intraspecific association (Van Houten et al. 1981) suggest that chemical perception may be important in the planktonic domain.

The following study examines chemosensory responses of planktonic larvae of Spirobranchus polycerus var. augeneri (ten Hove), a gregarious, intertidal serpulid found on cliffs at exposed sites on the coast of Barbados. Adult individuals are dioecious and gametes are broadcast in the sea. Development from fertilization to competence for settlement requires 12 to $14 \mathrm{~d}$ in the laboratory, Larvae are planktotrophic. The first objective of this project was to test for preferences that might serve to retain larvae near the adult site, using a species of alga commonly associated with adult worms and fragments of adult tubes. The second objective derives from the observation that larvae at the metatrochophore stage tend to form loose, temporary groups of closely spaced individuals. Such behaviour could result from an attraction between individual larvae. If such an attraction exists it might be expected to affect (1) the outcome of experiments in which larvae are drawn together as a result of a common response to a stimulus and (2) the distribution of larvae in the sea. The second objective of this study was to test for conspecific attraction between planktonic larvae of $S$. polycerus var, augeneri.

\section{MATERIALS AND METHODS}

Spirobranchus polycerus var. augeneri was collected at low tide at Martin's Bay on the east coast of Barbados between February and June 1986 and 1987, and at Round Rock on the southeast coast between February and June 1988, 1989 and 1990. Small aggregates (2 to $3 \mathrm{~cm}^{2}$ ) of intertwined tubes were taken from the undercut surface of coral limestone boulders or cliffs. Tubes were cracked open in the laboratory and 10 to 15 individuals of one sex placed in fingerbowls of seawater. Ripe individuals spawned within an hour. Ova and small guantities of spermatozod were then mixed in bowls of fresh seawater, placed in a water table at 26 to $29^{\circ} \mathrm{C}$ and maintained on a natural $(12: 12 \mathrm{~h})$ light: dark cycle. Larval cultures (usually 4 or 5 ) raised from a common group of parental worms were considered to form a batch. Cultures were fed every day on Isochrysis galbana (T strain) and Dunaliella sp. Culture water was changed every second day. Culture dishes were not aerated or otherwise agitated. Embryos begin to swim at about $6 \mathrm{~h}$ and differentiate into trochophores by $24 \mathrm{~h}$. A second trachal ring, the metatroch, becomes apparent between 3 and $4 \mathrm{~d}$. Post-trochal elongation of metatrochophore larvae continues during the subsequent 4 to $5 \mathrm{~d}$; larvae at this stage tend to form loose clusters; a second eyespot appears at 6 to $7 \mathrm{~d}$; differentiation of the first 3 setigers occurs at 9 to $10 \mathrm{~d}$ Three-setiger larvae of Spirobranchus bear a conspicuous red pigment spot on the pygidium. Larvae of $S$. giganteus and $S$. polycerus (stem var.) at this stage will occasionally settle in bowls in the laboratory. Larvae of $S$. polycerus var, augeneri have been raised to the 'red spot' stage but have never been seen to settle in the laboratory.

In this study it was assumed that the larval stages tested are, in nature, planktonic and not in contact with the substratum. In laboratory cultures larvae 1 to $8 \mathrm{~d}$ old swim actively and constantly, appearing to contact the bottom and sides of the culture dish only by accident, due to the confines of the container. The testing procedure used here was designed to prevent larvae making contact with the material being tested, i.e. to explore the sensitivity of planktonic larvae to waterborne substances originating from the materials placed in the testing chambers.

Larvae were tested between 10:00 and 14:00 h using experimental chambers constructed from two $10 \mathrm{ml}$ snap-cap polyethylene vials (Fig. 1 ) in which responding larvae were separated from the material being tested by $100 \mu \mathrm{m}$ plankton mesh. Larvae $1 \mathrm{~d}$ old, the smallest tested, are about $110 \mu \mathrm{m}$ in diameter: more than twice this if ciliary length is taken into account. Attracting vials contained the material being tested, i.e. algae, adult tube fragments, other larvae or, in the case of the control chamber, glass beads. Glass beads were also added to the larval vials to prevent floating. Larval vials (individually constructed) varied in volume from 2.5 to $3 \mathrm{ml}$. Chambers were assembled underwater, to exclude air, close to the inflow of fresh seawater into the water table. At the start of an experiment the test chamber(s) and a control chamber were placed side by side, oriented in the same direction, in the centre of a larval culture bowl. Culture bowls were $10 \mathrm{~cm}$ fingerbowls and each contained $200 \mathrm{ml}$ seawater and 500 to 9000 larvae (estimated from $2 \mathrm{ml}$ samples). Tests were carried out in large larval populations to ensure that the

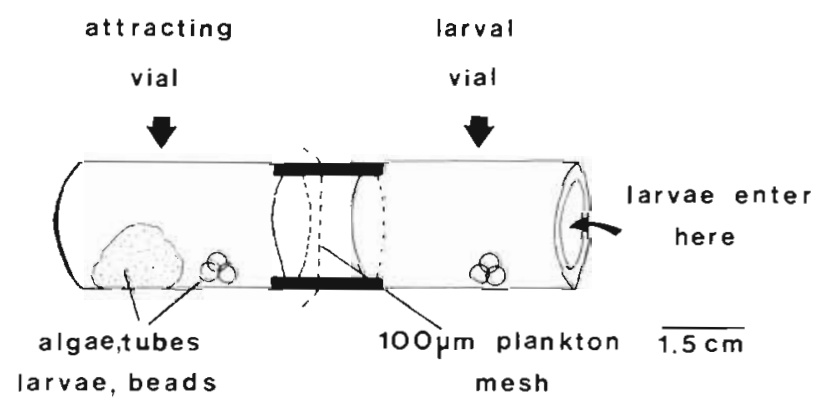

Fig. 1. Diagram of assembled experimental chamber 
number of larvae entering any one experimental chamber (never more than $9 \%$ of the larval population) did not significantly affect the probability of larvae entering the other chamber(s). Cultures containing less than 1000 larvae were always more than $6 \mathrm{~d}$ old. Mortality is high in the late metatrochophore stage in laboratory cultures. The only $6,7,8$ and 9 d results used in this study were obtained with cultures that subsequently proceeded to develop normally for another $2 \mathrm{~d}$. Once the chambers were in place the culture bowl was covered with aluminum foil to prevent any photoresponse, and left in the water table for $2 \mathrm{~h}$. Preliminary testing (Marsden et al. 1990) showed that when the bowl is covered the position of the chambers in relation to light sources in the laboratory does not affect larval responsiveness. The $2 \mathrm{~h}$ period was selected because preliminary trials indicated that longer periods sometimes resulted in dead larvae in the larval vial. At the end of an experiment the foil was removed; the open end of each larval vial was raised so that it just cleared the water surface and a $2 \mathrm{ml}$ sample was withdrawn using a $3 \mathrm{ml}$ hypodermic syringe. The content of the syringe was ejected onto a watch glass and larvae were counted by removing them, one at a time with a handdrawn micropipette under a dissecting microscope. The number of larvae per $2 \mathrm{ml}$ sample varied according to larval response and also according to the number of larvae in the culture used.

In the first group of experiments (Set 1) larvae were given a choice between Ulva lactuca, an alga common on rock flats adjacent to colonies of adult Spirobranchus polycerus var. augeneri, fragments of adult tubes and a control. Three small fronds (each about $1 \mathrm{~cm}^{2}$ ) of $U$. lactuca were placed in the attracting vial of one test chamber; a second vial was loosely packed with tube fragments and the third contained 6 glass beads. Ten experiments were carried out on larvae at each of 2,3 ,
$4,5,6$, and 7 to $9 \mathrm{~d}$. The data, i.e. the number of larvae per larval vial (max. 250; min. 0) were not distributed normally, even when transformed. Consequently nonparametric methods were used in statistical analyses. The data for Set 1 was assessed using a random block 2-way ANOVA on ranked data (Friedman's test; Zar 1984) for each age group, i.e. for larvae at each of 2,3 , $4,5,6$, and 7 to $9 \mathrm{~d}$. When the ANOVA indicated a significantly uneven distribution of larvae between chambers, Tukey's pairwise multiple comparisons test on ranked data was used to determine which chambers differed significantly from one another.

In Set 2 larvae were offered a choice between a control chamber and a test chamber containing 300 to 500 larvae from a culture in the batch being tested. Cultures of this density sometimes occurred naturally and when necessary were created by moving larvae from one bowl to another. Each experiment was carried out in a different larval culture bowl; cultures were tested at $2,3,4,5,6,7$, and 9 to $10 \mathrm{~d}$. The number of experiments carried out per larval age varied from 30 (for 3 d larvae) to 7 ( 7 to $10 \mathrm{~d}$ larvae) (see Table 2). The Wilcoxon paired sample test (Zar 1984) was used to evaluate differences, for each age group, between the number of larvae found in the larval vial of the control chamber and the number found in the larval vial of the test chamber carrying other larvae.

In the final group of experiments, Set 3, larvae were again offered a choice of 2 chambers: a control chamber and one containing larvae. In this set, however, larvae were also counted in a $2 \mathrm{ml}$ aliquot (mean of 2 samples) taken at the start of the experiment from the culture bowl in which the experiment had been conducted. The aliquot-control comparison was made as a test of the assumption that the control count represents a random $2 \mathrm{ml}$ sample. Ten experiments were carried out on larvae at each of 4,5 and $6 \mathrm{~d}$. The data for

Table 1. Spirobranchus polycerus var. augeneri. ANOVA (Friedman's test) of Set 1 data: N: number of experiments; U: mean number of larvae in larval vials of chambers containing Ulva lactuca; $\mathrm{T}$. mean number of larvae in larval vials of chambers containing adult tube fragments; $C$ : mean number of larvae in larval vials of control chambers; $\chi^{2}$ values and associated levels of probability $(p)$. Tukey's test: values for $q$ and associated levels of probability $(p)$. The position of the asterisk $\left({ }^{*}\right)$, to left or right of $q$ value, indicates which member of a pair is preferred

\begin{tabular}{|c|c|c|c|c|c|c|c|c|c|}
\hline \multicolumn{2}{|c|}{ Set 1} & \multicolumn{3}{|c|}{ Mean count } & \multicolumn{2}{|c|}{ Friedman's test } & \multicolumn{3}{|c|}{ Tukey's test } \\
\hline$N$ & Age & $\mathrm{U}$ & $I$ & $\mathrm{C}$ & $x^{2}$ & $\mathrm{p}$ & Pair & q & $\mathrm{p}$ \\
\hline 10 & $2 d$ & 33 & 42 & 26 & $<1.0$ & $>0.75$ & & & \\
\hline 10 & $3 \mathrm{~d}$ & 63 & 72 & 65 & 3.2 & $>0.05$ & & & \\
\hline 10 & $4 \mathrm{~d}$ & 44 & 25 & 27 & 1.55 & $>0.25$ & & & \\
\hline 10 & $5 \mathrm{~d}$ & 38 & 93 & 98 & 0.35 & $>0.75$ & & & \\
\hline 10 & $6 \mathrm{~d}$ & 18 & 32 & 27 & 3.8 & $>0.1$ & & & \\
\hline \multirow[t]{3}{*}{10} & $7-9 d$ & 33 & 50 & 34 & 15.2 & $<0.001$ & $\mathrm{~T} / \mathrm{C}$ & $\cdot 5.06$ & $<0.05$ \\
\hline & & & & & & & $\mathrm{T} / \mathrm{U}$ & $\cdot 4.43$ & $<0.05$ \\
\hline & & & & & & & $\mathrm{U} / \mathrm{C}$ & 0.63 & $>0.05$ \\
\hline
\end{tabular}


Table 2. Spirobranchus polycerus var augeneri. Wilcoxon Paired Sample test on Set 2 data. N: number of experiments; L: mean number of larvae per larval vial for chambers containing conspecific larvae; C: mean number of larvae per larval vial for control chambers; \%: percentage of mean total count; p: probability level

\begin{tabular}{|ccrrrrc|}
\hline $\mathrm{N}$ & Age & L & $\%$ & $\mathrm{C}$ & $\%$ & $\mathrm{P}$ \\
\hline 20 & $2 \mathrm{~d}$ & 35 & 51 & 34 & 49 & $>0.05$ \\
30 & $3 \mathrm{~d}$ & 30 & 50 & 32 & 50 & $>0.05$ \\
26 & $4 \mathrm{~d}$ & 36 & 56 & 29 & 44 & $<0.05$ \\
26 & $5 \mathrm{~d}$ & 51 & 78 & 15 & 22 & $<0.001$ \\
27 & $6 \mathrm{~d}$ & 39 & 60 & 26 & 40 & $<0.001$ \\
7 & $7-8 \mathrm{~d}$ & 29 & 78 & 8 & 22 & $<0.05$ \\
7 & $9-10 \mathrm{~d}$ & 3 & 43 & 4 & 57 & $>0.05$ \\
\hline
\end{tabular}

each age group was analyzed using Friedman's test, followed by Tukey's multiple comparisons when the null hypothesis, test count $=$ control count $=$ aliquot count, was rejected.

\section{RESULTS}

In Set 1, testing Ulva lactuca, adult tubes and a control, the distribution of larvae across the 3 chambers was uniform at all ages tested except the 7 to 9 day category (Friedman's test; $p>0.05$; Table 1); i.e. trochophore and early metatrochophore larvae (2 to $6 \mathrm{~d}$ old) show no preference for Ulva lactuca or adult tubes over the control. Late metatrochophore larvae ( 7 to $9 \mathrm{~d}$ old) show no preference for $U$. lactuca, but select adult tubes over the control (Wilcoxon test; $p<0.05$; Table 1). The data for Set 2 experiments show that larvae at 4 , 5,6 , and 7 to 8 d prefer larvae over a control (Wilcoxon. paired sample test; $\mathrm{p}<0.05$; Table 2). This preference is not expressed by 2 or $3 \mathrm{~d}$ larvae or by 9 to $10 \mathrm{~d}$ larvae (Wilcoxon paired sample test; $\mathrm{p}>0.05$; Table 2). Four day larvae are early metatrochophores, 7 to $8 \mathrm{~d}$ larvae are late metatrochophores. The validity of the negative result for 9 to $10 \mathrm{~d}$ larvae can be questioned on the grounds of very small sample size (total of 49 larvae counted in 7 experiments). These results suggest an interlarval attraction, active throughout the metatrochophore stage, but absent at the trochophore stage ( 2 and $3 \mathrm{~d}$ ) and possibly also at the 3 -setiger stage.

Set 3 data (Table 3), testing larvae, a control and an aliquot from the larval culture, indicates a preference by 5 and $6 \mathrm{~d}$ larvae for other larvae over both the control and the aliquot (Friedman's test; $p<0.05$; Table 3). In experiments on 4, 5, and $6 \mathrm{~d}$ larvae there is no significant difference between values for the control and the aliquot.

Two sets of experiments indicate an attraction between larvae, starting at 4 to $5 \mathrm{~d}$. No significant difference exists between control and aliquot counts in experiments on 4 to $5 \mathrm{~d}$ larvae, implying that in these experiments interlarval attraction did not significantly influence the number of larvae entering the control chamber. The maximum number of larvae per larval control vial in this set was 201. Larval vial counts in Sets 2 and 3 were never more than 250 and exceeded 200 in only 5 out of 143 experiments. Consequently it seems likely that differences in numbers of larvae between experimental and control chambers are the result of larval responses to a substance(s) diffusing across the plankton net barrier and not to an attraction between larvae accumulating in the larval vial and larvae at large' in the culture bowl.

\section{DISCUSSION}

The experimental data reported here indicate that planktonic larvae of Spirobranchus polycerus var. augeneri, from the early trochophore to the late metatrochophore stage, show no preference for exudates of Ulva lactuca, an alga common on reef flats adjacent to

Table 3. Spirobranchus polycerus var augeneri. ANOVA (Friedman's test) of Set 3 data. N: number of experiments; L: mean number of larvae per larval vial for chambers containing conspecific larvae; C: mean number of larvae per larval vial for control chambers; A: mean number of larvae in $2 \mathrm{ml}$ alıquot from larval culture $\chi^{2}$ values and associated levels of probability (p). Tukey's test: values for $q$ and associated levels of probability $(p)$

\begin{tabular}{|c|c|c|c|c|c|c|c|c|c|}
\hline \multicolumn{2}{|c|}{ Set 3} & \multicolumn{3}{|c|}{ Mean count } & \multicolumn{2}{|c|}{ Friedman's test } & \multicolumn{3}{|c|}{ Tukey's test } \\
\hline$N$ & Age & $\mathrm{L}$ & C & A & $x^{2}$ & $\mathrm{p}$ & Pair & ৭ & $\mathrm{p}$ \\
\hline 10 & $4 d$ & 22 & 23 & 16 & 3.47 & $>0.1$ & & & \\
\hline \multirow[t]{3}{*}{10} & $5 \mathrm{~d}$ & 28 & 18 & 13 & 6.80 & $<0.05$ & $\mathrm{~L} / \mathrm{A}$ & $\cdot 4.20$ & $<0.01$ \\
\hline & & & & & & & $\mathrm{C} / \mathrm{A}$ & 1.12 & $>0.50$ \\
\hline & & & & & & & $\mathrm{L} / \mathrm{C}$ & $\cdot 4.46$ & $<0.01$ \\
\hline \multirow[t]{3}{*}{10} & $6 \mathrm{~d}$ & 27 & 16 & 17 & 7.29 & $<0.01$ & $\mathrm{~L} / \mathrm{A}$ & $\cdot 4.71$ & $<0.005$ \\
\hline & & & & & & & $\mathrm{C} / \mathrm{A}$ & 0.0 & $>0.50$ \\
\hline & & & & & & & $\mathrm{L} / \mathrm{C}$ & $\cdot 4.71$ & $<0.005$ \\
\hline
\end{tabular}


adult worm colonies. Late metatrochophore larvae show a preference for exudates of adult tubes but younger planktonic stages do not. This study does not, therefore, demonstrate, for early planktonic stages of $S$. polycerus var. augeneri, any preference for aspects of the adult substrate comparable to the preference for certain reef corals reported for young larvae of $S$. giganteus (Marsden \& Meeuwig 1990, Marsden et al. 1990). In the latter studies it was suggested that the preferences of planktonic stages might represent an early (at 2 to 3 d) expression of a preference important in habitat selection at the time of settlement, i.e. at the end of larval life. A preference for adult tube fragments by late metatrochophores of $S$. polycerus var. augeneri could likewise represent an early, but not as early (at $7 \mathrm{~d}$ ), expression of a behaviour pattern important at settlement (about $10 \mathrm{~d}$ ). A preference, at metamorphosis and settlement, for some component of the adult tube has been shown for larvae of several gregarious tubiculous polychaetes (Wilson 1968, 1970, 1977, Straughan 1972, Eckelbarger 1978, Scheltema et al. 1981, Jensen \& Morse 1984, Pawlik 1986). The timing of the onset of the early expression of a preference important at settlement could be related to the role of this behaviour in the life of the planktonic larva. It has been suggested that the coral preferences of S. giganteus larvae might serve to retain early larval stages over the reef (Marsden et al. 1990). Retention has been demonstrated for coral larvae within a reef area (Sammarco \& Andrews 1985) and for larvae of Phyllodoce mucosa and Lanice conchilega in the Bay of Archachon (Mathivat-Lalier \& Cozaux 1990). Young trochophore larvae of Spirobranchus polycerus var. augeneri are photonegative (Marsden 1990), a behaviour that may move them into subsurface off-shore currents and so prevent retention.

This study also demonstrates a preference for exudates of conspecific larvae of the same age by metatrochophore larvae of Spirobranchus polycerus var. augeneri. Trochophore larvae and 3-setiger larvae did not show this preference. The evidence for the trochophore stage is reasonably good but the data for the 3 -setiger stage is sparse (only 49 larvae counted) Metatrochophore larvae have routinely been observed, in laboratory cultures, to form loose, temporary clusters of up to about 50 individuals. An interlarval chemical attraction could presumably lead to cluster formation. Aggregation prior to settlement has been observed for some cirripede (Grosberg 1982), polychaete (Levin 1986) and scallop (Tremblay \& Sinclair 1990) larvae. Massive local recruitment of serpulids Galeolaria (O'Donnell 1988) and S. polycerus var. augeneri (pers obs.) suggests similar behaviour. If $S$. polycerus var. augeneri larvae are not retained near the spawning site, a pre-settlement accumulation of pre-competent larvae, which then develop an attraction to adult tubes, is a reasonable scenario

The observations reported here and elsewhere (Marsden \& Meeuwig 1990, Marsden et al. 1990) on chemotactic behaviour by Spirobranchus larvae are essentially pilot studies, leaving many questions unaddressed. The concentrations of attracting materials used are arbitrary, e.g. enough tube fragments or blades of alga to fill a 2.5 to $3 \mathrm{ml}$ attracting vial or 300 to 500 larvae or a $3 \mathrm{~mm}^{3}$ piece of live coral. The $2 \mathrm{~h}$ time span was selected because longer periods resulted in some dead larvae in the larval vials. The minimum distance over which the attractive substances acted is $30 \mathrm{~mm}$, i.e. the distance between the opening into the larval vial and the plankton netting barrier separating attracting and larval vials. There are few comparisons available for the interpretation of results. The concentration of larvae used in the attracting vials in this study may be high in terms of natural aggregations; it is about 500 to 800 times that reported for aggregations of Polydora larvae by Levin (1986) and 300 times reported mysid concentrations (Carleton \& Hamner 1989). On the other hand the distance between attracting substance and responding larva in this study may be rela. tively large; it is about 300 times that reported for chemodetection of food by calanoid copepods (Price 1988). Because there is little information on densities of larvae in natural aggregations or on distances across which chemodetection takes place by planktonic animals, the applicability of the results reported here is impossible to evaluate. Tests using varied distances and concentrations would be helpful to future work in this area. These initial studies on planktonic larvae of Spirobranchus indicate a capacity to respond positively to water-borne exudates of tubes and conspecific larvae. The expression of these capacities appears to vary with larval age. We need to learn much more about these capacities before attempting any prediction of their role in the natural life of the larva.

Acknowledgements. This work was supported by an Operating Grant from the National Science and Engineering Research Council of Canada to J. R. Marsden. The author is indebted to Dr. Wayne Hunte for the use of facilities at the Bellairs Research Institute in Barbados.

\section{LITERATURE CITED}

Banse, K. (1986). Vertical distribution and horizontal transport of pelagic larvae of echinoderms and benthic polychaetes in an open coastal sea. Bull. mar. Sci. 39: 162-175

Carleton, J. H., Hamner, W. M. (1989). Resident mysid community structure, abundance and small scale distribution in a coral reef lagoon. Mar. Biol. 102: 461-472

Crisp, D. J. (1974). Factors influencing the settlement of marine invertebrate larvae. In: Grant, W., Mackie, G. 
(eds.). Chemoreception in marine organisms. Academic Press, New York, p. 177-265

Doyle, R. W. (1974). Choosing between darkness and light: the ecological genetics of photobehaviour in the planktonic larvae of Spirorbis borealis. Mar. Biol. 25: 311-317

Eckelbarger, K. J. (1978). Metamorphosis and settlement in the Sabellariidae. In. Chia, F.-S., Rice, M. E. (eds.). Settlement and metamorphosis of marine invertebrate larvae. Elsevier, New York, p. 127-144

Ennis, G. P. (1975). Behavioral responses to changes in hydrostatic pressure and light during larval development of the lobster Homarus americanus. J. Fish. Res. Bd Can. 32: 271-281

Forward, R. B. Jr (1989a). Depth regulation of larval marine decapod crustaceans: test of an hypothesis. Mar. Biol. 102 195-202

Forward, R. B. Jr (1989b). Behavioral responses of crustacean larvae to rates of salinity change. Biol. Bull mar. biol. Lab., Woods Hole 176: 229-238

Forward, R. B., Costlow, J. D. (1974). The ontogeny of phototaxis by larvae of the crab Hithropanopeus harrissi. Mar. Biol. 26: 27-33

Forward, R. B. Jr, Cronin, I W., Stearns, D. E. (1984). Control of diel vertical migration: photoresponse of a larval crustacean. Limnol. Oceanogr. 29: 146-154.

Grosberg, R. K. B. (1982). Intertidal zonation of barnacles: the influence of planktonic zonation of larvae on vertical distribution of adults. Ecology 63: 894-899

Hadfield, M. G. (1986). Settlement and recruitment of marine invertebrates: a perspective and some proposals. Bull. mar. Sci. 39: $418-425$

Jackson, G. .A. (1986). Interaction of physical and biological processes in the settlement of planktonic larvae. Bull. mar Sci. 39: 202-212

Jacoby, C. A., Youngbluth, M. J. (1983). Mating behaviour in three species of Pseudodiaptomus (Copepoda: Calanoida). Mar. Biol. 76: 77-86

Jensen, R. A., Morse, D. E. (1984). Intraspecific facilitation of larval recruitment: gregarious settlement of the polychaete Phragmatopoma californica (Fewkes). J. exp. mar. Biol. Ecol. 83: 107-126

KoehI, M. A. R. (1985). Mechanisms of particle capture by copepods at low Reynolds numbers: possible modes of selective feeding. In Meyer, D. G., Strickler, J. R. (eds.) Trophic interactions within aquatic ecosystems. Westview Press, Boulder, p. 135-166

Latz, M. I., Forward, R. B. Jr (1977). The effect of salinity upon phototaxis and geotaxis in a larval crustacean. Biol. Bull. mar. biol. Lab., Woods Hole 153: 163-179

Levandowsky, M. J., Hauser, D. C. R. (1978). Chemosensory responses of swimming algae and Protozoa. Int. Rev. Cytol. 53: $145-210$

Levin, L. (1986). The influence of tides on larval availability in shallow waters overlying a mudflat. Bull. mar Sci. 39: 224-233

Mackas, D. L., Denman, K. L., Abbott, M. R. (1985). Plankton patchiness: biology in the physical vernacular Bull mar. Sci. 37. 652 -674

Marsden, J. R. (1984). Swimming in response to light by larvae of the tropical serpulid Spirobranchus giganteus. Mar. Biol. 83: 13-16

Marsden, J. R. (1986). Response to light by trochophore larvae of Spirobranchus giganteus: effects of level of irradiance, dark adaptation and spectral distribution. Mar Biol. 93: 13-16

Marsden, J. R. (1987). Coral preference behaviour by planktonic larvae of Spirobranchus giganteus corniculatus (Serpulidae: Polychaeta). Coral Reefs 6: 71-74
Marsden, J. R. (1988). Light responses of the larva of the serpulid polychaete Galeolaria caespitosa. Mar. Biol. 99: $397-407$

Marsden, J. R. (1990). Light responses of planktonic larvae of the serpulid Spirobranchus polycerus (Schmarda). Mar. Ecol. Prog. Ser. 58: 225-233

Marsden, J. R, Conlin, B. E., Hunte, W (1990). Habitat selection in the tropical polychaete Spirobranchus giganteus (Pallas): 2. Larval preferences for corals. Mar Biol. 104: 93-99

Marsden, J. R., Meeuwig, J. (1990). Preferences of planktonic larvae of the tropical serpulid Spirobranchus giganteus (Pallas) for exudate of corals from a Barbados reef. J. exp mar. Biol. Ecol. 137: 95-104

Mathivat-Lallier, M.-H., Cozaux, C. (1990). Larval exchange and dispersion of polychaetes between a bay and the ocean. J. Plankton Res. 12: 1163-1172

O'Connor. N. J., Epifano, C. E. (1985). The effect of salinity on the dispersal and recruitment of fiddler crab larvae. J. Crustacean Biol. 5: 137-145

O'Donnell, M. A. (1988). The ecology and early life history of the intertidal tubeworm, Galeolaria caespitosa. Aust. J. Ecol. 13: 236-237

Ohman, M. D. (1990). The demographic benefits of diel vertical migration by zooplankton. Ecol. Monogr. 60: 257-281

Paffenhöfer, G. A.. Strickler, J. R., Alcarez, M. (1982). Suspension-feeding by herbivorous calanoid copepods: a cinematographic study. Mar. Biol. 72: 193-200

Pawlik, J.R. (1986). Chemical induction of larval settlement and metamorphosis in the reef-building tube worm Phragmatopoma californica (Sabellariidae: Polychaeta). Mar. Biol. 91: 59-68

Price, H. J. (1988). Feeding mechanisms in marine and freshwater zooplankton. Bull mar. Sci. 43: 327-343

Sammarco, P. W., Andrews, J. C. (1985). Localized dispersal and recruitment in Great Barrier Reef corals: the Helix experiment. Science 239: 1422-1424

Scheltema, R. S. (1974). Biological interactions determining larval settlement of marine invertebrates. Thalassia jugosl. 10: $263-296$

Scheltema, R. S., William, I. P., Shaw, M. A., Loudon, C. (1981). Gregarious settlement by the larvae of Hydroides dianthus (Polychaeta: Serpulidae). Mar Ecol. Prog. Ser. 5: $69-74$

Stancyk, S. E., Feller, R. J. (1986). Transport of non-decapod invertebrate larvae in estuaries: an overview. Bull. mar. Sci. 39: $257-268$

Strathmann, R. R. (1990). Why life histories evolve differently in the sea. Am. Zool 30: 197-207

Straughan, D. (1972). Ecological studies of Mercierella enigmatica Fauvel (Annelida: Polychaeta) in the Brisbane River. J. Anim. Ecol 41.93-136

Sulkin, S. D., Kelly, P., van Heukelem, W (1980). The behavioral basis of larval recruitment in the crab Callinectes sappidus Rathbun: a laboratory investigation of ontogenetic changes in geotaxis and barotaxis. Biol. Bull. mar. biol. Lab., Woods Hole 159: 402-417

Tremblay, M. J., Sinclair, M. (1990). Diel vertical migration in sea scallop larvae Placopecten magellanicus in a shallow embayment. Mar. Ecol. Prog. Ser. 67- 19-25

Van Alstyne, K. L. (1986). Effects of phytoplankton taste and smell on feeding behaviour in the copepod Centropages hamatus. Mar Ecol. Prog. Ser. 34: 187-190

Van Houten, J. D., Hauser, C. R., Levandowsky, M. J. (1981) Chemosensory behaviour in Protozoa. In: Levandowsky, M. J. Hunter, S. H. (eds.) Biochemistry and physiology of Protozoa. Academic Press, New York, p. 67-124 
Verity, P. G. (1988). Chemosensory behaviour in marine planktonic ciliates. Bull, mar Sci. 43: 772-782

Wilson, D. P. (1968). The settlement behaviour of the larva of Sabellaria aveolata (L). J. mar. biol. Ass. U. K. 48: 387-435

Wilson, D. P. (1970). The larvae of Sabellaria spinulosa and their settlement behaviour. J. mar. biol. Ass. U. K. 50: 330-352

Wilson, D. P. (1977). The distribution, development and settlement of the sabellarian polychaete Lygdamis muratus (Allen) near Plymouth. J. mar biol. Ass. U. K. 57: 761-792

This article was submitted to the editor
Yoshioka, P. M. (1986). Chaos and recruitment in the bryozoan Membranipora membranacea. Bul]. mar. Sci. 39: $408-417$

Young, C. M., Chia, F-S. (1982). Ontogeny and phototaxis during larval development of the sedentary polychaete, Serpula vermicularis (L). Biol. Bull mar. biol. Lab., Woods Hole 162: 457-468

Zar, J. H. (1984). Biostatistical analysis. Prentice Hall Inc., Englewood Cliffs

Manuscript first received: June 15, 1989

Revised version accepted: January 24, 1990 